\title{
Intensive lipid-lowering therapy in high-risk diabetic patients
}

\author{
Masaaki Miyata ${ }^{1}$
}

Received: 7 September 2021 / Accepted: 14 September 2021 / Published online: 25 October 2021

(C) The Japanese Society of Hypertension 2021

Hypertension, dyslipidemia, and diabetes mellitus (DM) are major risk factors for atherosclerotic diseases, and there are several recommendations for their treatment. Regarding low-density lipoprotein cholesterol (LDL-C) levels, the European Society of Cardiology/European Atherosclerosis Society cholesterol guidelines recommend a target LDL-C level $<55 \mathrm{mg} / \mathrm{dl}$ in patients with very high risk and $<70 \mathrm{mg} /$ dl in patients with high cardiovascular (CV) risk [1]. Regarding intensive lipid-lowering therapy, Khan et al. performed a meta-analysis of 11 randomized controlled trials (130,070 patients) comparing intensive lipid-lowering therapy (LDL-C $<70 \mathrm{mg} / \mathrm{dl}$ ) and less-intensive lipid-lowering therapy (LDL-C $\geq 70 \mathrm{mg} / \mathrm{dl}$ ) [2]. Compared with the less-intensive lipid-lowering therapy, intensive lipidlowering therapy was significantly associated with the lower risk of all-cause mortality [risk ratio (RR) 0.94 (95\% confidence interval $0.89-1.00), P=0.04], \mathrm{CV}$ mortality [RR 0.90 (0.81-1.00), $P=0.04$ ], myocardial infarction [RR 0.80 (0.72-0.90), $P<0.001]$, cerebrovascular events [RR 0.81 (0.73-0.90), $P<0.001]$, and major adverse cardiovascular events (MACEs) [RR 0.89 (0.84-0.93), $P<0.001$ ]. Although concerns exist that extremely low levels of LDL$\mathrm{C}$ can enhance the risk of cancer, DM, and hemorrhagic stroke, there are no significant differences between intensive lipid-lowering and less-intensive lipid-lowering therapies in terms of cancer, DM, or hemorrhagic stroke. The researchers concluded that treatment to achieve LDL-C levels below $70 \mathrm{mg} / \mathrm{dl}$ using intensive lipid-lowering therapy can safely reduce the risk of mortality and MACEs.

DM patients tend to have multiple risk factors, not only hyperglycemia but also hypertension, dyslipidemia, and insulin resistance. DM patients develop microvascular complications, including retinopathy, nephropathy and neuropathy, and

Masaaki Miyata

miyatam@m3.kufm.kagoshima-u.ac.jp

1 School of Health Sciences, Faculty of Medicine, Kagoshima University, Kagoshima, Japan macrovascular complications, such as stroke, coronary artery disease (CAD), and peripheral artery disease (PAD) [3]. To prevent these diabetic complications, glycated hemoglobin A1c (HbA1c) less than 7.0\%, systolic blood pressure (SBP) lower than $130 \mathrm{mmHg}$, diastolic blood pressure (DBP) lower than $80 \mathrm{mmHg}$, LDL-C lower than $120 \mathrm{mg} / \mathrm{dl}$, high-density lipoprotein cholesterol (HDL-C) $40 \mathrm{mg} / \mathrm{dl}$ or greater, triglycerides lower than $150 \mathrm{mg} / \mathrm{dl}$, and non-HDL-C lower than $150 \mathrm{mg} / \mathrm{dl}$ are recommended for DM patients in all guidelines in Japan [4-6]. Furthermore, LDL-C lower than $100 \mathrm{mg} / \mathrm{dl}$ and non-HDL-C lower than $130 \mathrm{mg} / \mathrm{dl}$ are recommended for DM patients with CAD, and LDL-C lower than $70 \mathrm{mg} / \mathrm{dl}$ and nonHDL-C lower than $100 \mathrm{mg} / \mathrm{dl}$ are recommended for high-risk DM patients with CAD in Japan (Fig. 1). Although DM patients undergo revascularization procedures for $\mathrm{CAD}$ or PAD, the outcomes are less favorable than those of non-DM patients. Therefore, intensive preventive therapy through the combination of diet, exercise, and optimal medical therapy is important for DM patients to reduce their $\mathrm{CV}$ risk and prevent CV events and disability.

To explore the potential benefits of treat-to-target therapy in very high-risk DM patients, Itoh et al. investigated the incidence of $\mathrm{CV}$ events with intensive lipid-lowering therapy (LDL-C $<70 \mathrm{mg} / \mathrm{dl}, \quad n=2518$ ) or standard lipidlowering therapy (LDL-C $100-120 \mathrm{mg} / \mathrm{dl}, n=2524$ ) in DM patients with hypercholesterolemia, diabetic retinopathy, and no history of CAD [7]. The standard versus intEnsive statin therapy for hypercholesteroleMic Patients with diAbetic retinopaTHY (EMPATHY) study used a multicenter, prospective, randomized, open-label, blinded end point (PROBE) design. The primary outcome was the composite incidence of $\mathrm{CV}$ events, including cardiac, cerebral, renal, and vascular events, or CV-associated death. They found no significant decrease in CV events or CVassociated deaths with intensive therapy, possibly because the between-group difference in LDL-C was lower than they expected $(27.7 \mathrm{mg} / \mathrm{dl}$ at 36 months of treatment).

Then, to identify patients who will benefit from intensive statin therapy among high-risk DM patients without prior $\mathrm{CV}$ diseases, Shinohara et al. reported the subanalysis of the 


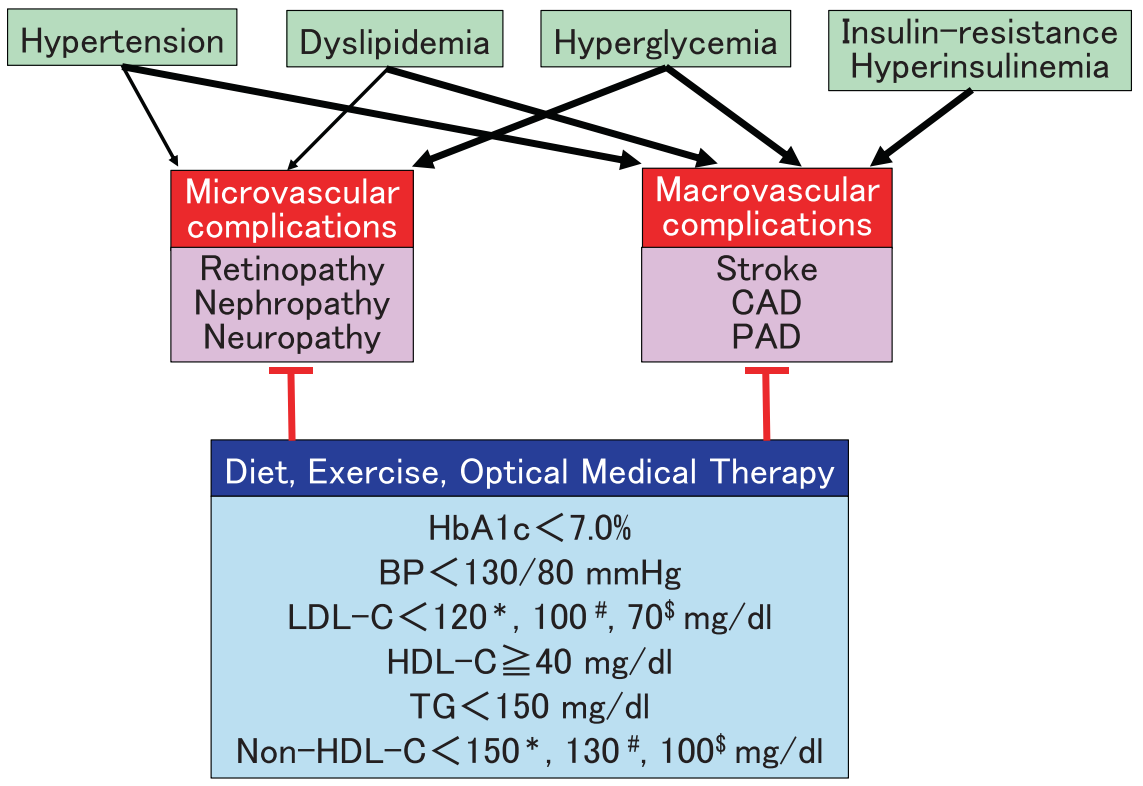

Fig. 1 Multiple risk factors and complications in DM patients. DM diabetes mellitus, CAD coronary artery disease, PAD peripheral artery disease, HbA1c glycated hemoglobin A1c, BP blood pressure, LDL-C

EMPATHY study [8]. The 4980 patients enrolled in the EMPATHY study were divided into $\mathrm{BP} \geq 130 / 80 \mathrm{mmHg}$ (SBP $\geq 130 \mathrm{mmHg}$ and/or DBP $\geq 80 \mathrm{mmHg}, n=3335$ ) and $\mathrm{BP}<130 / 80 \mathrm{mmHg}(n=1645)$ subgroups according to baseline BP levels. Intensive statin therapy with a target LDL-C of $<70 \mathrm{mg} / \mathrm{dl}$ significantly reduced the primary outcome compared with standard statin therapy with a target LDL-C of $100-120 \mathrm{mg} / \mathrm{dl}$ in DM patients with $\mathrm{BP} \geq 130 / 80$ $\mathrm{mmHg}$ but not in those with $\mathrm{BP}<130 / 80 \mathrm{mmHg}$. Their findings suggested that intensive $\mathrm{BP}$ control $(\mathrm{BP}<130 / 80$ $\mathrm{mmHg}$ ), similar to intensive LDL-C control (LDL-C $<70$ $\mathrm{mg} / \mathrm{dl}$ ), is also useful for the prevention of CV events in high-risk DM patients with hypertension and hypercholesterolemia. Combined optimal therapy is important for highrisk patients with multiple risk factors.

Hypertriglyceridemia is an important residual risk factor for $\mathrm{CV}$ diseases in DM patients after the reduction of LDL$\mathrm{C}$ with statin, ezetimibe, and proprotein convertase subtilisin kexin 9 antibody inhibitors. Fibrates, nicotinic acids, and n-3 polyunsaturated fatty acids are used for the treatment of hypertriglyceridemia. In patients with hypercholesterolemia and hypertriglyceridemia, combined therapy with stains and fibrate is recommended by JAS guidelines, and these treatments can be carefully combined [6]. The creatine kinase level and liver and renal function need to be checked before and after this combined therapy to screen for rhabdomyolysis or liver and renal dysfunction.

\section{Compliance with ethical standards}

Conflict of interest The author declares no competing interests. low-density lipoprotein cholesterol, HDL-C high-density lipoprotein cholesterol, TG triglyceride, $\downarrow$ progression, T protection. $*$ DM patients without CAD, ${ }^{*} \mathrm{DM}$ patients with $\mathrm{CAD},{ }^{\$}$ high-risk DM patients with $\mathrm{CAD}$

Publisher's note Springer Nature remains neutral with regard to jurisdictional claims in published maps and institutional affiliations.

\section{References}

1. Mach F, Baigent C, Catapano AL, Koskinas KC, Casula M, Badimon L, et al. 2019 ESC/EAS Guidelines for the management of dyslipidaemias: lipid modification to reduce cardiovascular risk. Eur Heart J. 2020;41:111-88.

2. Khan SU, Khan MU, Virani SS, Khan MS, Khan MZ, Rashid M, et al. Efficacy and safety for the achievement of guidelinerecommended lower low-density lipoprotein cholesterol levels: a systematic review and meta-analysis. Eur J Prev Cardiol. 2020. https://doi.org/10.1093/eurjpc/zwaa093.

3. Beckman JA, Creager MA, Libby P. Diabetes and atherosclerosis epidemiology, pathophysiology, and management. JAMA. 2002;287:2570-81.

4. Araki E, Goto A, Kondo T, Noda M, Noto H, Origasa H, et al. Japanese clinical practice guideline for diabetes 2019. Diabetol Int. 2020;11:165-223.

5. Umemura S, Arima H, Arima S, Asayama K, Dohi Y, Hirooka Y, et al. The Japanese Society of Hypertension Guidelines for the Management of Hypertension (JSH 2019). Hypertens Res. 2019;42:1235-481.

6. Kinoshita M, Yokote K, Arai H, Iida M, Ishigaki Y, Ishibashi S, et al. Japan Atherosclerosis Society (JAS) guidelines for prevention of atherosclerotic cardiovascular diseases 2017. J Atheroscler Thromb. 2018;25:846-984.

7. Itoh H, Komuro I, Takeuchi M, Akasaka T, Daida H, Egashira Y, et al. Intensive treat-to-target statin therapy in high-risk Japanese patients with hypercholesterolemia and diabetic retinopathy: report of a randomized study. Diabetes Care. 2018;41:1275-84.

8. Shinohara K, Ikeda S, Enzan N, Matsushita S, Tohyama T, Funakoshi K, et al. Efficacy of intensive lipid-lowering therapy with statin stratified by blood pressure levels in patients with type 2 diabetes mellitus and retinopathy: insight from the EMPATHY study. Hypertens Res. 2021. https://doi.org/10.1038/s41440-02100734-x. Online ahead of print. 